\title{
¿Puede haber un mal uso de la razón? Sensibilidad, entendimiento y razón (Schelling, Baader y Jacobi)
}

\section{Could it be that there is an improper use of reason? Sensibility, understanding and reason (Schelling, Baader, Jacobi)}

\author{
Ana CARRASCO-CONDE \\ (Universidad Complutense de Madrid)
}

Recibido: 03/03/2014

Aceptado: 09/04/2015

\section{Resumen}

La propuesta contrapone tres autores (Jacobi, Baader y Schelling) en un momento concreto de la historia de la filosofía para analizar el diálogo que se establece entre ellos a través sus respectivos textos: Ueber gelehrte Gesellschaften, ihren Geist und Zweck (Jacobi, 1807); Ueber die Behauptung: dass kein uebler Gebrach der Vernunft sein könne (Baader, 1807) y Philosophische Untersuchungen über das Wesen der menschlichen Freiheit und die damit zusammenhängenden Gegenstände (Schelling, 1809), con el fin, por un lado, de atender a la relación e influencia recíproca entre ellos, y, por otro, de pensar a partir de ellos si el uso en sí mismo de la razón es causante (y responsable) del mal, si la aparición de éste tiene que ver con un mal uso de ella o, siguiendo una antigua tradición filosófica, el origen del mal se sitúa en la sensibilidad o en el entendimiento.

Palabras clave: Jacobi, Baader, Schelling, razón, entendimiento, sensibilidad, mal.

\section{Abstract}

The proposal opposes three authors (Jacobi, Baader and Schelling) in a certain moment of the history of the philosophy on having analyzed the dialog that establishes between them through their respective texts: Ueber gelehrte Gesellschaften, 
ihren Geist und Zweck (Jacobi, 1807); Ueber die Behauptung: dass kein uebler Gebrach der Vernunft sein könne (Baader, 1807) and Philosophische Untersuchungen über give Wesen der menschlichen Freiheit und die damit zusammenhängenden Gegenstände (Schelling, 1809), in order to answer to the question about if the reason is the causer of the evil, if can exists an evil use of it, or if evil, following the philosophical tradition, has its origin in the sensibility or in the understanding.

Keywords: Jacobi, Baader, Schelling, reason, understanding, sensibility, evil.

Al principio fue un hilo que, invisibilizado voluntariamente, hizo que el caballo del doctor del pueblo cayera cuando éste cabalgaba hasta las caballerizas. Después el hijo del barón apareció, inconsciente, tras haber sido cruelmente apaleado, como le sucedió al niño de la comadrona, nacido con deficiencias mentales. Un pájaro es atravesado con unas tijeras y depositado encima de la mesa del pastor, como castigo ante su ferrea disciplina. Con el transcurrir de las escenas y las descripciones facilitadas por una voz en off que nos acompaña como narrador en esta historia, sabemos, indirectamente, que también los otros actos constituyen una forma perversa de ajusticiamiento: si el doctor cayó del caballo, el niño fue apaleado y al hijo de la comadrona se le infligió una salvaje tortura, fue porque el primero abusaba de su hija, el segundo era el hijo del explotador barón, y el niño con síndrome de Down recibía en su cuerpo las flagelaciones que -supuestamente- su madre adultera se merecería. A través de estas escenas, contenidas en La cinta blanca (Das weiße Band, Haneke, 2009), el director despliega una reflexión sobre el origen del mal: si es éste causa de una educación estricta, que cosecha algo diferente a lo que siempra, si la maldad tiene que ver con el pecado (de ahí la necesidad de la cinta blanca: para que el blanco de la cinta constituya, al menos, un rasgo externo de pureza de quien carece de ella), si más bien es producto de un mal entendimiento de lo que el bien significa (como atestiguan estos actos de brutal "ajusticiamiento") o si, simplemente, la maldad tiene que ver con la crueldad y ésta, a su vez, con un instinto "animal" ínsito en el hombre que se ampara en las dobleces de la "moral" para dar rienda suelta a su perversidad de corazón, por decirlo con el Kant de Lacan.

Las reflexiones de Haneke con las que hemos comenzado estas líneas, abordan una problemática, la del origen del mal, que tiene una larga tradición en la historia de la filosofía: desde la opinión de Sócrates, para el cual toda acción contraria a la virtud sólo puede ser originada por una falta de conocimiento, hasta las conocidas (y muchas veces mal entendidas) tesis de Hannah Arendt sobre la banalidad del mal, pasando por Plotino para el que, según el libro VIII de la Primera Enéada, el mal -los males, dicho con más propiedad- no serían sino una privación o carencia de 
bien ligado a la materia, una antiesencia que sólo alcanza su sentido como aquello más alejado del Bien1, o por San Agustín, que, tras su etapa maniqueísta, para responder al Unde malum? responsabiliza al hombre de su surgimiento: el mal moral no sería sino una corrupción del bien asociado a la libertad humana, de ahí que la pregunta no sea ahora tanto por el origen del mal, sino por aquello que hace que hagamos el mal. También Spinoza abordará en la Ética esta cuestión con su conocida tesis según la cual no existen ni el bien ni el mal en sí, sino lo bueno o lo malo para mi² o Leibniz, cuya solución, en la Teodicea, que hace del mal parte del orden universal exculpando así del mal a la divinidad, no deja de plantear otro tipo de problemas, desde lo que él mismo denomina fatum mahometanum ${ }^{3}$ hasta lo que el propio Schelling le reprochará acerca de su malum metaphysicum y del supuesto mejor mundo de los posibles ${ }^{4}$. Es la reelaboración de la pregunta por parte de San Agustín, Unde malum faciamus?, la que otorga otra dimensión -y bien enigmática- al problema del mal al arrojarlo al ámbito del acto, de la voluntad y del libre arbitrio, como señala Paul Ricoeur en su texto sobre el mal5, más enigmática aún si cabe si es que hay que abordar el mal desde el punto de vista físico, metafísico y físico como hiciera Leibniz.

En este contexto filosófico y con estos estratos de pensamiento sobre la cuestión del mal se da en torno a 1807 una disputa que recoge todas estas tradiciones y enfrenta entre sí las tres fuentes principales de las que podría surgir el mal, ligado ya siempre al ámbito de la libertad humana: la sensibilidad (Gefühl), el entendimiento (Verstand) y la razón (Vernunft). Volviendo a la película de Haneke se trata-

\footnotetext{
1 Plotino: Enéada I, VIII.

2 Spinoza: Ética, parte IV, Proposiciones VIII y XXX. Ver también la correspondencia con Blijenbergh: Las cartas del mal. Correspondencia Spinoza y Blijenbergh, Buenos Aires, Caja Negra, 2008.

3 Leibniz: Essais de théodicée. Sur la bonté de Dieu, la liberté de l'homme et l'origine du mal, GF Flammarion, Paris, 1969, p. 30.

4 Las obras de Schelling se citarán siguiendo la Sämtliche Werke $(=S W)$ editada por el hijo de Schelling, Karl Friedrich August, publicada en Cotta (Stuttgart. 1856-1861) y dividida en dos secciones (I. vols. 1-10; II. Vols. 1-4). Esta edición será reproducida posteriormente en la edición de M. Schröter en Beck/Oldenburg. Múnich. 1927-1954, aunque con otra ordenación (6 vols. principales; 6 vols. complementarios). Se citará del siguiente modo: las secciones en números romanos, seguido del número de volumen, también en arábiga, después aparecerá el número de página con números arábigos (ej.: $S W \mathrm{I} / 7, \mathrm{n}^{\circ}$ pág.). Cuando exista, se citará también la traducción al castellano tras punto y coma (Ejemplo completo: SW I/7, $\mathrm{n}^{\mathrm{o}}$ pág.; trad. $\mathrm{n}^{\mathrm{o}}$ pág.). En este caso, el texto se encuentra en las Philosophische Untersuchungen über das Wesen der menschlichen Freiheit (1809). Existe traducción al castellano a cargo de Helena Cortés y Arturo Leyte: Investigaciones filosóficas sobre la esencia de la libertad humana y los objetos con ella relacionados, Anthropos, Barcelona, 2000. Cuando la traducción sea modificada se señalará convenientemente. En este caso la crítica a Leibniz se encuentra en SW I/7, 367-369; 187-191, así como en SW I/7, 401; 269; también en Las lecciones muniquesas de historia de la filosofia moderna $S W \mathrm{I} / 10,57$ y ss.

5 Ricoeur, P.: El mal. Un desafio a la filosofía y a la teología, Amorrortu, Buenos Aires, 2006, p. 37.
} 
ría de averiguar si el acto libre malo tendría algo que ver con la naturaleza propia del hombre, que sería, ante todo una bestia; si el acto malo no es tan malvado como pudiera parecer porque se produciría como consecuencia de una mala interpretación de la norma; o si, finalmente, el mal se relaciona de alguna forma con la razón a través de una decisión sopesada y consciente, con un acto voluntariamente realizado contra la norma. Los protagonistas de esta discusión serán F.H. Jacobi, en ese momento ilustre Presidente de la Academia de las Ciencias de Baviera, Franz von Baader y F.W.J. Schelling. Al primero le deberemos el origen de la polémica puesto que fue su discurso en julio de 1807, en ocasión de los fastos de la Academia, titulado Sobre las sociedades cientificas, su espíritu y finalidad6, el desencadenante al analizar la distancia insalvable que separa al hombre y de las bestias con el fin, en último término, de abordar la cuestión de en qué consiste la razón y qué es lo que nos hace seres racionales ${ }^{7}$. El texto de Jacobi no es especialmente original o argumentativamente destacable pero es, sin embargo filosóficamente relevante por sus consecuencias, entre ellas, la respuesta de Franz von Baader que no se hizo esperar y que apareció publicada, también en 1807, en un breve escrito de apenas cinco páginas que da título a nuestro artículo: Sobre la afirmación de que no puede haber un mal uso de la razón ${ }^{8}$. Sobre algunas de la reflexiones de Baader aparecidas en este enjundioso texto se articulará uno de los trabajos más imprescindibles cuando se trata de abordar filosóficamente el problema del mal publicado apenas año y medio después: las Investigaciones filosóficas sobre la esencia de la libertad humana y los objetos con ella relacionados escrito por F.W.J. Schelling en la que la pregunta Unde malum faciamus? se transformará en "¿de dónde [woher] procede aquello en lo que reside este ente [Seiende], la base [Basis] que constituye propiamente al mal?"9. Para analizar esta discusión y abordar la cuestión del origen del mal y en qué sentido puede ser entendido como un ente (Seiende) vertebraré mi texto en tres partes: 1. Unschuld (Inocencia) y Gesinnung (Sentimiento); 2. Unvernunft

\footnotetext{
6 "Ueber gelehrte Gesellschaften, ihren Geist und Zweck" (en adelante GGZ). En Jacobi, J.H.: Werke, vol. 5.I, Frommann-holzboog, pp. 325-386. Edición de Klaus Hammacher y Walter Jaeschke.

7 Interesante es hacer notar que tan sólo cuatro años después y estrecha relación con la discusión que se establecerá estos años, Jacobi escribirá contra Schelling su Von den göttlichen Dingen und ihrer Offenbarung (1811), en la que le acusará, como antes a Mendelsohn, Kant y Fichte, de spinozista y fatalista (Jacobi, J.H.: Werke, vol. 3, 3-136). Sobre esta polémica desde sus inicios puede consultarse Cfr. Rivera de Rosales, J. - Cubo, Ó. (eds.): La polémica sobre el ateísmo. Fichte y su época, Dykinson, Madrid, 2009. Existe una numerosa bibliografía centrada en las relaciones entre Jacobi y Schelling, baste señalar al clásico de Weischedel como introdución a Sobre las cosas divinas: "Jacobi und Schelling. Eine philosophische-theologische Kontroverse", Darmstadt, Wissenschaftliche Buschgesellchaft, 1969.

8 "Ueber die Behauptung: dass kein uebler Gebrach der Vernunft sein könne" (en adelante KÜGV). En Baader, F. von: Sämmtliche Werke, vol I, Ed. Franz Hoffmann, Leipzig, Herrmann Bethmann, 1851, pp. 33-38.
}

${ }_{9} S W \mathrm{I} / 7,153$; trad. modif. 353. 
(Sinrazón) y Verkehrtheit (Perversión); 3. Umkehrung (Inversión) y Erhebung (Elevación).

\section{Unschuld (Inocencia) y Gesinnung (Sentimiento)}

Jacobi afirmaba expresamente en su discurso que el origen del mal no puede encontrarse de ningún modo en un "mal uso de la razón", dado que es ésta la que nos diferencia de las bestias. La razón sería, según Jacobi, la que nos convierte en seres morales; la fuente de toda verdad y el motor del progreso humano, la que nos hace, en definitiva, hombres: es, por ello esencialmente humana. Pero si es la razón la que nos diferencia de las bestias y es la razón la que introduce el componente de la moralidad, entonces el interrogante, casi obligado es que si los animales no hacen el mal y permanecen siempre en estado de inocencia, ¿recae en la razón la responsabilidad de una acción mala? En absoluto, sostendrá Jacobi: la causa del mal ha de situarse no en la sensibilidad (Gefühl), en cuyo caso a las bestias se les podría abscribir acciones malas, ni tampoco en la razón (Vernunft), que es una facultad "divina" y origen de nuestra moralidad, sino en el entendimiento (Verstand) cuando éste es cegado por la sensibilidad.

Veamos esto más despacio: en su discurso Jacobi afirmará que hombres y bestias tienen en común el sentimiento y el entendimiento, pero en cambio no la razón y que es precisamente en el entendimiento en el que ha de situarse el origen del mal, que no es nada positivo, ni el resultado de una decisión puramente racional y consciente, sino "un mal uso del entendimiento cuando éste está oscurecido por la sensibilidad"10. Desde el punto de vista de Jacobi, el entendimiento (Verstand), siguiendo en esto a Kant (que entiende la razón como entendimiento), tendría que asociarse con la capacidad de formar conceptos en las reflexiones sobre las cosas sensibles y finitas y no tendría forma alguna de acceder al incondicionado. Por eso su función será -seguimos aquí el discurso- la de ordenar el conocimiento sensible y determinar los medios necesarios para la satisfacción de las necesidades (lo útil), dicho de otra manera su ámbito de aplicación es el de la sensibilidad y su organización. En el caso de un animal el entendimiento le permitiría emplear unos medios y no otros para conseguir su objetivo: correr tras su presa o bien, por ejemplo, cercarla sigilosamente según sea la circunstancia. De ahí que el entendimiento "ignora lo que es bueno o malo y sólo conoce lo que es más y lo que es menos"11, es decir, que el entendimiento es "útil" pero no bueno. No aplica calificaciones morales. La razón (Vernunft), en cambio, es la que lleva al hombre a un nivel "superior", libre de las cadenas del instinto y constituye la facultad originaria, incorruptible e inmutable,

$10 G G Z$, p. 362.

11 GGZ, p. 358. 
que nos proporciona autonomía y libertad 12 : hace al hombre conocedor de la virtud, de lo bueno y de lo verdadero para que aspire por un lado "a la autodeterminación moral" y, por otro, "al autodespliegue verdadero"13. Sin embargo, es preciso hacer notar que el concepto de razón en Jacobi, poco tiene que ver con lo que por ella entenderán Baader o Schelling (por no mencionar el criticismo y el idealismo casi en su totalidad14): dando un salto mortale sostendrá que la razón es sentimiento, ligado a un Dios personal. En las Cartas sobre la doctrina de Spinoza (1785) la definirá del siguiente modo: "Apelo a un sentimiento [Gesinnung] indenegable e irresistible como primer fundamento inmediato de toda filosofía y religión; a un sentimiento que garantiza al hombre íntimamente que él tiene un sentido de lo suprasensible. Llamo a este sentido razón [Vernunft], a diferencia de los sentidos, dirigidos a un mundo visible"15.

12 “[...] el entendimiento se desarrolla en el hombre antes que la razón, lo que quiere decir que deviene inteligente de una forma animal antes de hacerlo de una forma humana. La razón no se desarrolla en absoluto, es decir, que ella no procede, como en el caso del entendimiento, de la experiencia sensible y de la reflexión. Si fuera el caso, la razón no sería si no un entendimiento espiritualizado. Aparece solamente más tarde y se manifiesta como una facultad superior, como una autoridad más elevada, es necesario que ella se eleve teóricamente por encima de la ciencia que trata sobre la naturaleza y, a nivel práctico, por encima de una moral". Citado en P.P. Schneider: Die «Denkbücher» F.H. Jacobis, Stuttgart, Frommann-holzbogg, 1986, IV, 9, p. 269.

13 GGZ, p. 360 y ss.

14 En Kant la razón, muy cerca del entendimiento, será la "facultad superior del conocimiento" (Cfr. $K r V$ A 835/B 863), frente a la inferior que es, justamente, la sensibilidad; y el entendimiento "la facultad de producción espontánea de representaciones" (Cfr. $\mathrm{KrV}$, A51/B 75).

15 El texto de las Spinoza-Briefe se encuentra en Jacobi, J.H.: Werke, op.cit., vol. 1,1 y 1,2. En cuanto a Schriften zum Spinozastreit ( $=S p$.-Br.) la edición es de Klaus Hammacher y Irmgard-Maria Piske. Es preciso hacer notar que Jacobi en 1812 volvió a publicar, corregidas, las Spinoza-Briefe para la Ausgabe letzter Hand de sus Werke (Leipzig 1812-1825; en cuatro volúmenes). La primera edición de las Spinoza-Briefe fue la de 1785 y la segunda de 1789. Existe una edición de bolsillo muy manejable en Meiner al cuidado de Marion Lauschke basada en el texto de 1785. Hay traducción al castellano basada en el texto de 1789: Cartas a Mendelssohn y otros textos, Madrid, Círculo de Lectores, 1996, con prólogo, traducción y notas de J.L. Villacañas. Para profundizar en la disputa pueden consultarse: Die Hauptschrift zum Pantheismusstreit zwischen Jacobi und Mendelssohn, editado por Heinrich Scholz, Verlag von Reuther \& Reichard. Berlin, 1916 en la que se encuentra una recopilación casi exhaustiva de los documentos de esa polémica. También el estudio de Kurt Christ: Jacobi und Mendelssohn. Eine Analyse des Spinozastreits. Königshausen \& Neumann. Würzburg. 1988 ; así como el clásico estudio de Hans Hölters: Der spinozistische Gottesbegriff bei M. Mendelssohn und J.H. Jacobi und der Gottesbegriff Spinozas. Universitas-Archiv. Verlag-Anstalt Heinr. \& J. Lechte / Emsdetten. 1938. Citamos el texto como Sp.-Br. correspondiente la edición Ausgabe letzter Hand de sus Werke, seguido del número de página, así como, tras punto y coma, la paginación correspondiente a la traducción de J.L.Villacañas cuando se ha hecho uso de ella. En este caso $S p$.-Br. IV-1, p. 20. Para profundizar en el concepto de razón en Jacobi, veáse el trabajo de W. Jaeschke: "Eine Vernunft, welche nicht die Vernunft ist. Jacobis Kritik der Aufklärung”, en Jaeschke, W.-Sandkaulen, B. (ed.): Friedrich Heinrich Jacobi. Eine Wendepunkt der geistigen Bildung der Zeit, Meiner, Hamburgo, 2004, pp. 199-216. 
La razón por tanto no puede tener un "mal uso" porque si bien es cierto que el entendimiento puede ser cegado cuando se deja llevar por la sensibilidad, la razón, en cambio, es un sentimiento que escapa a toda perversión. De este modo según Jacobi, que sigue aquí una larga tradición que hemos mencionado anteriormente, el entendimiento constituirá el punto clave para entender el origen del mal: lo que se opone al cielo, afirmará Jacobi, no es el infierno (que implicaría aceptar una dimensión "malvada"), sino la tierra. Por lo dicho, los planteamientos de Jacobi se acercarán y mucho a un socratismo que reduce la moral a autoconocimiento16. El mal surge necesariamente de una "ignorancia pasiva", que no afecta a la razón puesto que es el resultado de la influencia de lo sensible sobre el entendimiento. El entendimiento permite conectar la sensibilidad con la razón y, por tanto, funciona a la manera de una bisagra: si se usa correctamente y sigue a la razón, conduce a la humanidad a la virtud; si se erige en instancia única y "bloquea" a la razón condena a la humanidad. Karl Homann en su clásico libro F.H. Jacobis Philosophie der Freiheit 17 analizará pormenorizadamente la exégesis de la distinción entre entendimiento y razón para darle una dimensión política: el discurso de Jacobi que opone entendimiento y razón en el fondo está enfrentando ciencia (lado del entendimiento, en tanto ámbito del cálculo y la organización) y progreso (lado de la razón y de la consecuención de la virtud). El mal acontecería con la "confusión del entendimiento" en un humo doble de brujas 18 porque el entendimiento no podría acceder con claridad -y este concepto es fundamental- a lo verdadero. Habría, pues, un desconocimiento (Verleugnen).

Desde este punto de vista la libertad quedaría reducida a Faktum der Vernunft en la forma de un hegemonía del principio inteligente sobre lo sensible y los apetitos. No una elección racional de lo mejor, sino una independencia de la voluntad respecto del apetito ${ }^{19}$. Algo que, por otro lado, supondría un desarrollo de las reflexiones de sus primeros años en las que se esforzaba en oponer razón e instinto, entre "bien real" y "bien aparente", sólo que aquí, en 1807, el instinto, dado que nubla el

16 Cfr. Villacañas Berlanga, J.L.: Nihilismo, especulación y cristianismo en F-H. Jacobi, Anthropos/Universidad de Murcia, Barcelona, 1989, p. 513.

17 Homann, K.: F.H. Jacobis Philosophie der Freiheit, Karl Alber, Freiburg, 1973, pp. 125-134.

18 "En un humo doble de brujas, llamado espacio y tiempo, andan como trasgos los fenómenos en los que nada aparece. [...] Así sólo sentimos nuestra propia sensibilidad, que nunca es receptora de algo verdadero: sólo intuye su interior intuyente, tanto a posteriori como a priori”. Jacobi, F.H.: Werke, vol. 3, p. 111. Citado por J.L. Villacañas en Nihilismo, especulación y cristianismo en F.H. Jacobi, op. cit., p. 480.

19 Así lo sostendrá ya en 1785: "La libertad no reside pues en una facultad insensata de decidirse sin razones, ni en la elección de lo mejor entre lo útil, ni en el deseo racional; pues incluso si dicha elección tuviera lugar según los conceptos más abstractos, siempre se produciría mecánicamente. La libertad consiste, por esencia, en la independiencia de la voluntad respecto del apetito". En Sp.-Br. 27; Cartas a Mendelssohn y otros textos, op. cit., (trad. modif) p. 74. 
entendimiento, conducirá al hombre no a un bien aparente, sino al mal. No hay, pues, por lo dicho, para Jacobi, libertad para el mal y el mal queda convertido en nada despojado de cualquier tipo de fuerza o entidad propias y relacionado con un problema de conocimiento y de apariencia. Nos encontramos con un "odio nihilista frente a la sensibilidad" que basa la moralidad en este nihilismo, como formula José Luis Villacañas en su monografía sobre Jacobi ${ }^{20}$. El mal no puede nunca ser una decisión basada en la libertad que da el conocimiento pleno, sino el producto de un engaño. Volviendo a la película de Haneke, las acciones de los niños vendrían dadas de una mala comprensión de la moral, de un engaño: la sensibilidad nublaría el entendimiento y obturaria el acceso a la verdad y a la virtud facilitado por la razón, haciendo dependiente a la voluntad del apetito. Un ajusticiamiento, pues, mal entendido: una forma de "bien aparente" con la que se engaña el espíritu que se desconoce $^{21}$. De forma que aunque nuestra sustancia espiritual, relacionada con la razón, nos encamina hacia el bien, este camino no es seguro porque se encuentra, como escollo, con la naturaleza: la sensibilidad afecta al entendimiento hasta tal punto que desemboca en la conciencia egoísta, en la manifestación del interés propio. El hombre para triunfar moralmente necesita un conocimiento profundo de su espíritu.

\section{Unvernunft (Sinrazón) y Verkehrtheit (Perversión)}

El primero en reaccionar ante esta interpretación fue Franz von Baader que, en el mismo año de 1807 -pocas semanas después de aquel discurso- publicó en el número 197 de la revista Morgenblatt una explícita respuesta a este "mal uso del entendimiento": "Sobre la afirmación: que no puede haber un mal uso de la razón". Unvernunft alude a este texto y con él hace una crítica explícita la concepción de la razón incorruptible de Jacobi22. Esta postura, afirma Baader tajantemente, no es correcta $^{23}$ porque "vemos sin duda alguna - escribe Baader- cómo la razón humana [Vernunft] deviene sinrazón [Unvernunft], pero en el sentido positivo de una perversión [Verkehrtheit] y corrupción [Corruption]"24. En su escrito, por tanto, Baader

\footnotetext{
20 Villacañas Berlanga, J.L.: Nihilismo, especulación y cristianismo en F.H. Jacobi, op. cit., p. 515.

21 Véase la interesante correspondencia que Jacobi establece con su maestro Le Sage en 1767. En una carta del 12 de diciembre, en la que responde a la de La Sage que centraba la cuestión en el mito de Pandora para interrogarse por el origen del mal y el papel de Dios en el hecho de que lo malo aparece muchas veces ante los ojos del hombre como bello y bueno, Jacobi se pregunta por qué esos males se sienten como buenos y la respuesta, que pasa por la lectura inevitable de Spinoza, es que el mal es la nada de una naturaleza aparente, una apariencia con la que se engaña el espíritu que desconoce. $\mathrm{AB}$, I, 21 .

$22 K \ddot{U} G V, 35$ y 36 .

$23 K \ddot{U} G V, 36$.

${ }_{24} K \ddot{U} G V, 37$.
} 
atacará la concepción de Jacobi, que hacía del mal una pasiva deficiencia, una cuestión de supremacía de instintos, y afirmará que lo que nos mueve a obrar mal no es lo que tenemos en común con los animales, sino precisamente lo que nos diferencia de ellos, es decir, la razón ${ }^{25}$. El mal no tiene que ver simplemente con la mácula de lo sensible, sino con algo positivo y ligado a la libertad que sí tiene que ver con una elección; no procede ni del entendimiento ni de la naturaleza o de lo sensible, sino de una razón "pervertida" y, por tanto, "corruptible", es decir, susceptible de un mal uso. Si el mal se limitara al triunfo ciego de los apetitos no tendría sentido hablar de un "mal moral", por eso lo que ha de investigarse es el mal que vive y experimenta el hombre en su realidad efectiva, con su dimensión objetiva (el mal en el mundo) y otra subjetiva (el mal en el hombre singular).

Para desarrollar su propuesta, Baader recuperará la lectura que Kant hizo del "mal radical" para afirmar, contra Jacobi, que el mal es un principio positivo que tiene una relación directa con la razón y con la inversión del orden moral cuando los intereses particulares priman sobre la comunidad o, dicho de otro modo cuando el amor propio (Selbstliebe) actúa en beneficio del yo y no del nosotros ${ }^{26}$. Es más, según Baader, la renuncia al uso de la razón es ya, como decíamos, en sí algo positivo: la falta de razón o sinrazón (Unvernunft) ha de ser entendida en un sentido positivo, no meramente privativo o defectuoso, como una perversión (Verkehrtheit) o como una corrupción (Corruption) "de la cual se sigue que lo humano se transforma en inhumano, la naturaleza en no-naturaleza y la forma y figura se desfiguran [o deforman]"27. Según Baader, aunque puede afirmarse que el hombre cuando se abandona a la animalidad -digamos, a los impulsos-niega algo positivo movido por un "supuesto" desconocimiento (Verleugen), como sostiene Jacobi, este desconocimiento de la razón no puede entenderse como "una pasiva ignorancia [Ignoriren], sino [como] un acto [Act] del ánimo [Gemüth] positivo, dinámico y violento"28 asociado con la elevación [Erhebung] del querer "propio" de una "mala mismidad [schlechten Selbsheit]"29.

\footnotetext{
$25 \mathrm{KU} G V, 36-37$.

26 Hay numerosa bibliografía al respecto para analizar el mal radical en Kant, por ello remito a un par de títulos: Fischer, N.: "Das >radikale Böse $<$ in der menschlichen Natur. Kants letzter Schrift im Denken der Freiheit". En: Danz, C.-Langthaler, R (ed): Kritische und absolute Transzendenz. Religionsphilosophie und Philosophische Theologie bei Kant und Schelling, Múnich, Karl Alber, 2006; Schulte, C.: Radikal böse. Die Karriere des Bösen von Kant bis Nietzsche, Múnich, Wilhelm Fink Verlag, 1998: Es importante destacar que para Kant, como para Schelling, el mal moral está relacionado con la razón y con una decisión de la libertad, por lo que para ambos el mal es un acto positivo de la libertad.

$27 K \ddot{U} G V, 37$.

$28 K \ddot{U} G V, 38$.

${ }^{29} K \ddot{U} G V$, p. 38.
} 
Esta elevación, mencionada por Baader, el concepto de una mismidad "mala" y el "amor propio" (Selbstliebe) de origen kantiano (y ecos rousseaunianos ${ }^{30}$ ) serán fundamentales en la propuesta que Schelling plantea para comprender el mal y su relación con la "esencia de la libertad humana" precisamente porque este intento de divinización de la voluntad propia será la que constituya el mal, de forma que para Schelling, como para Baader, el mal es ante todo inversión, pero -y esto es lo característico de la propuesta de Schelling - una inversión hecha efectiva que altera el mundo en su totalidad e introduce la catástrofe a través de una decisión libre, es decir, por un mal uso de la razón o un uso inadecuado de la razón que "desboca" al fundamento. Por eso en Schelling, que sigue muy de cerca de Baader, la libertad del hombre es una capacidad de hacer el bien o el mal, porque puede elegir, no como Dios: por eso la efectividad del mal y su surgimiento en el mundo es algo que sólo está en manos del hombre 31 .

Por lo dicho, si el mal es producto de una decisión, es también por si mismo un acto, el resultado de un hacer que viene posibilitado por una libertad que no remite, como lo hacía ver Jacobi, al mero dominio sobre lo sensible. De ahí la conocida definición que aparece en el Escrito sobre la libertad: "el concepto real y vivo es el de que la libertad es una capacidad para el bien y para el mal"32. Dado que únicamente el hombre es libre, es a través de éste como puede hacerse el mal efectivo a través de una decisión que sólo le incumbe a él y que afecta tanto al hombre en sí mismo en el orden moral, como a la entera creación, y, por tanto, tanto al orden histórico como, lo que es más inquietante, al natural ${ }^{33}$. En directa referencia a las posiciones de Jacobi en aquel discurso de 1807, Schelling afirmará en 1809: "Las representaciones de nuestra época, mucho más superficiales y que empujan el filantropismo hasta la negación del mal, no tienen la menor relación con tales ideas. Según éstas, el único fundamento del mal reside en la sensibilidad o en la animalidad o el principio terrestre, en cuanto que no le contraponen al cielo el infierno, como debieran, sino la tierra. Esta representación es una consecuencia natural de la teoría según la cual la libertad reside en el mero dominio del principio inteligente sobre los apetitos e inclinaciones sensibles y el bien procede de la pura razón, con lo cual, como es comprensible, no existe ninguna libertad para el mal [...]; para decirlo más claro,

\footnotetext{
30 Sobre el amor propio y el amor de sí en Rousseau puede consultar el artículo de Vera Waksman: "Jean-Jacques Rousseau: el amor a sí mismo y la felicidad pública" en Anacronismo e irrupción. Revista de Teoría y Filosofía Política Clásica y Moderna, vol. 3, № (2013), pp. 104-127.

31 Cfr. $S W$ I/7, 373; 201; también $S W$ I/7, 381; 221: "el mal permanece siempre una elección propia del hombre".

$32 \mathrm{SW} \mathrm{I} / 7,352 ; 151$.

33 Sobre el problema de la decisión y la elección, me permito remitir al artículo Carrasco-Conde, A.: "Decisión y elección o la afilada sección del instante. La libertad en Schelling y la influencia de Kant en el Freiheitsschrift (1809)". En Daimon. Revista de Filosofia, Suplemento 2 (2008), pp. 347-354.
} 
se anula completamente el mal, pues la debilidad o inefectividad del principio del entendimiento puede, en efecto, ser el fundamento de la falta de acciones buenas y virtuosas, pero no de las acciones positivamente malas y contrarias a la virtud" 34 . Ahora bien, ¿qué relación puede haber entre el mal y los distintos órdenes arriba enumerados, el moral, el histórico y el natural? ¿cómo es posible que sea la razón misma la que nos lleva a hacer el mal? ¿qué significa que sea la libertad la condición de posibilidad del mal? ¿de dónde viene que hagamos el mal?

El título completo del texto de 1809, Investigaciones filosóficas sobre la esencia de la libertad humana y los objetos con ella relacionados, responde ya, aunque implícitamente, a estas preguntas porque esos temas o asuntos que tratan de recogerse en el título, son, como enumerará Schelling en las "Palabras preliminares" la voluntad, la personalidad y el sistema ${ }^{35}$, que tratan de ser presentados no como una parte nueva e independiente de su trabajo anterior, sino como complemento de la misma, la parte ideal, que, eso sí, es expuesta ahora por primera vez con total precisión. Es importante, pues, tener en cuenta que el problema del mal se conecta con la filosofía de la naturaleza y que, por tanto lo que se ha denominado la "filosofía de la libertad" está relacionada con la Naturphilosophie36. Así, por cierto, lo hace

34 SW I/7, 371-372; 197.

35 Cf. SW I/7, 333-334; 103-105.

${ }^{36}$ Habría que puntualizar, en primer lugar, que la filosofía de Schelling, frente a una mala comprensión de la evolución y articulación de su filosofía que ha querido ver en ella una amalgama de doctrinas cuya sucesión de etapas revelaría su falta de vertebración interna, constituye un sistema armado de evolución coherente cuyo objetivo fue siempre el mismo: tratar de explicar el paso de lo incondicionado a lo condicionado. El gran tema, en torno al despliegue del Absoluto y a sus formas, daría lugar a una filosofía cuyo núcleo sería el devenir mismo y que explicaría las preocupaciones posteriores del filósofo por la "historicidad" (Geschichtlichkeit) y el tiempo. Pero aún más: en esta historicidad y en este devenir del Absoluto habrá dos temas que permanecerán siempre como inquietudes del filósofo: el mal y, en estrecha relación con éste y el pasado, el mito. Es preciso hacer notar que los dos primeros textos escritos por el filósofo versan en un caso sobre el mal, su "Antiquissimi de prima malorum humanorum origine philosophematis Genes. III. explicandi tentamen criticum et philosophicum" (1792), y en otro sobre los mitos: "Über Mythen, historische Sagen und Philosopheme der ältesten Welt" (1793). Es cierto que la pregunta por estos temas no es explícita en algunas de sus obras, como las pertenecientes a la Naturphilosophie, pero no es menos cierto que, esta preocupación en sus primeras reflexiones filosóficas conecta con sus obras intermedias y finales, de forma que, cuando vuelve a abordar estos temas, éstos encajan con las otras "partes" del sistema. Por eso, aunque en la elaboración de la Naturphilosophie Schelling no estaba preocupado por desarrollar una reflexión sobre el mal y aunque hay una evolución evidente en muchos de sus planteamientos, pueden sin embargo rastrearse muchos elementos en estos trabajos que se asociarán a su investigación sobre el mal, lo que le llevará a asociar la actividad real y la fuerza contractiva con aquello que posteriormente pueda ser entendido como elemento definitorio del mal. Recuérdese en este sentido la importancia de sus estudios en medicina y cómo éstos son introducidos en su explicación del mal en 1809 a través del concepto de enfermedad. Sobre la continuidad en la obra de Schelling, remito a mi artículo "Die Struktur des Werdens bei Schelling", En: Asmuth, C. - Wibke, R. (eds.): Paradoxien des Selbst, Würzburg, Verlag Königshausen \& Neumannn, 2014. 
ver explícitamente el filósofo cuando establece la distinción -fundamental- de sus "investigaciones filosóficas" sobre la libertad entre "el ser en cuanto que existe y el ser en cuanto mero fundamento de la existencia"37, distinción a través de la cual Schelling procede a explicar el proceso de constitución del sistema -o de la realidad, si se quiere- a través del despliegue en la naturaleza en torno a la lucha de dos fuerzas antitéticas y, lo que es más importante, será clave para entender el objeto principal del Escrito sobre la libertad, es decir: el mal ${ }^{38}$. Este despliegue constituye el proceso por el cual el Absoluto se hace a sí mismo o toma conciencia de sí: es decir que el Absoluto no es algo ya dado desde el comienzo, sino algo en proceso de construcción constante que hace que, como tal, el Absoluto no deba ser entendido como "punto de partida" sino como "punto de llegada"39. Toda la realidad es ya el despliegue del Absoluto puesto que se genera al mismo tiempo que se despliega el Absoluto, de ahí que Schelling pueda afirmar que todo queda dentro del sistema, aunque el sistema tiene, como la luna, una cara oculta que jamás podrá ser manifiesta, sino a lo sumo intuida a través de sus efectos (como el mal) o, si se quiere, de sus síntomas (como en la naturaleza o, incluso, en la historia). La culminación del proceso de este Sujeto absoluto supone su "efectiva realización" (Verwirklichung), aunque no la supresión, cancelación, asunción o integración (Aufhebung) de su "lado oscuro", sino tan solo su contención o superación trabajo-

\footnotetext{
37 Aunque a lo largo del artículo se trataraá de explicar someramente esta distinción, remitimos ahora al lector, entre la abundante bibliografía sobre el tema, a los trabajos de O. Höffe- A. Pieper (Eds.): Über das Wesen der menschlichen Freiheit, Berlín, Akademie Verlag 1995 y, dentro de esta obra colectiva, al artículo de Jörg Jantzen "Die Möglichkeit des Bösen", pp. 61-90; H.M. Baumgartner - W.G. Jacobs (Eds.): Schellings Weg zur Freiheitsschrift. Legende und Wirklichkeit, Stuttgart, Frommanholzboog 1996; J. Hennigfeld: Friedrich Wilhelm Joseph Schellings > Philosophische Untersuchungen über das Wesen der menschlichen Freiheit und die damit zusammenhängenden Gegenstände<, Darmstad, Wissenchaftliche Buchgesellschaft, 2001. Con ocasión del bicentenario han sido publicados recientemente dos trabajos de gran interés: G. Wenz: Das Böse und sein Grund. Zur Rezeptionsgeschichte von Schellings Freiheitsschrift 1809: Vorgelegt in der Sitzung vom 9. Juli 2010, Múnich, Bayerische Akademie der Wissenschaften 2010; S. Peetz - R. Elm: Freiheit und Bildung: Schellings Freiheitsschrift 1809-2009, Paderborn, Fink 2011; Danz, C.-Jantzen, L. (Eds.): Gott, Natur, Kunst und Geschichte. Schelling zwischen Identitätsphilosophie und Freiheitsschrift, Vienna University Press, Viena, 2011; Carrasco Conde, A.: La limpidez del mal. El mal y la historia en la filosofía de F.W.J.Schelling, Madrid, Plaza y Valdés, 2013. También es preciso citar el libro colectivo al cuidado de Diogo Ferrer y Teresa Pedro: Schellings Philosophie der Freiheit. Studien zu den Philosophischen Untersuchungen über das Wesen der menschlichen Freiheit, Würzburg, Ergon, 2012, que incluye trabajos de Marquet, Courtine, Hay, Carrasco Conde, Galland-Szymkowiak, Cattin, Rivera de Rosales, Gabriel, Asmuth, Zöller, Goddard y Lore Hühn entre otros. También citamos, por imprescindible, el estudio de M. Heidegger: Schellings Abhandlung über das Wesen der menschlichen Freiheit (1809), Tubinga, Max Niemeyer 1971.

$38 \mathrm{SW} \mathrm{I} / 7,357 ; 163$.

39 La idea de "punto de llegada" asociada al Absoluto aparece en Marquet, F.: Liberté et existence. Étude sur la formation de la pensée de Schelling, Paris, Gallimard, 1973, p. 396 y ss.
} 
sa (Überwindung $)^{40}$. Podría interpretarse que con este movimiento lo que se manifiesta es lo concebible y asimilable por la razón, mientras que, lo que permanece oculto tiene que ver con la imposibilidad de integrar algo dentro de un sistema de medida o catalogación ${ }^{41}$. Dicho de otra forma: si el resto "irreductible" no se deja absorber ni anular por el concepto es porque, este resto está literalmente fuera del alcance de la red racional: se le escapa continuamente, hasta el punto de que no se trata de "lo que a la razón le sobra" sino aquello que ni siquiera puede rozar. El mal en este sentido sería forma de aparición (Schein) o de manifestación, un síntoma de lo que se encuentra oculto para el concepto, aquello que es "impensable" y que, de aparecer, supone algo terrorífico para el ansia de catalogación de lo "racional". El resto, pues, no se manifiesta ni puede manifestarse jamás, sino que lo que se muestra es un síntoma que da prueba de su irradicable y latente presencia, al igual que una repetición es síntoma de algo reprimido (de ahí las interesantes y fecundas relaciones establecidas entre Schelling y el psicoanálisis) ${ }^{42}$.

El Grund o "el fundamento" de la existencia y la existencia misma o, mejor, del "ser, en cuanto que existe" son parte de un mismo sistema-o, dicho con Schelling, son Dios- de forma que Dios, siguiendo con nuestra analogía con la luna, tiene una cara inconsciente, que no es Él mismo pero que es inseparable de Él porque -y aquí abandonamos la analogía lunar- constituye su fundamento -no lógico, sino real-, la base sobre la que se levanta para devenir poco a poco consciente de sí: "Puesto que no hay nada anterior o exterior a Dios, éste debe tener en sí mismo el fundamento de su existencia. Esto lo dicen todas las filosofías, pero hablan de tal fundamento como de un mero concepto, sin convertirlo en algo real y efectivo. Ese fundamento de su existencia que Dios tiene en sí mismo, no es Dios considerado absolutamente, esto es, en cuanto que existe, pues es sólo lo que constituye el fundamento de su existencia, es la Naturaleza -en Dios, un ser inseparable de Él, pero sin embargo distinto de Él"43. Para explicar esta relación entre Dios como existente

40 Sobre la importancia radical de esta diferenciación y las consecuencias que tendrá para la filosofía contemporánea y las filosofías de la diferencia, desde Deleuze a Zizek, remito al lector a CarrascoConde, A.: "Schelling, Zizek, Baudrillard: la lógica del fantasma". En Anales del Seminario de Historia de la Filosofía, vol. 30, No 2 (2013), pp. 505-525. Para profundizar en la imposibilidad de manifestación del Resto y su relación con el síntoma, me remito a Zizek, S.: Bienvenidos al desierto de lo real, Madrid, Akal, 2002.

41 De ahí la idea de "resto irreductible": "Tras el hecho eterno de la autorrevelación, todo es en el mundo - tal y como lo vemos ahora- regla, orden y forma, pero, con todo, lo carente de regla subyace siempre en el fundamento, como si pudiera volver a brotar de nuevo, y en ningún lugar parece que el orden y la forma sean lo originario, sino como si se hubiera ordenado algo inicialmente y sin regla. He aquí la inasible base de la realidad de las cosas, el resto que nunca se puede reducir, aquello que ni con el mayor esfuerzo se deja disolver en el entendimiento, sino que permanece eternamente en el fundamento". SW I/7, 359-360; 167-169.

42 Cfr. Ffytche, M.: The Foundation of the unconscious. Schelling, Freud and the birth of the modern Psyche, Cambrigde University Press, 2012.

$43 \mathrm{SW}$ I/7, 357-358; 163. 
(como el Sujeto que deviene consciente) y su fundamento Schelling emplea una analogía con la luz y la gravedad, ambas fuerzas, una expansiva (la luz) y otra contractiva (la gravedad): como Sujeto del proceso quiere ser sí mismo y tomar conciencia de sí, y por ello sale a la luz, se busca, pero al mismo tiempo, al querer ser sí mismo, se contrae sobre sí. Aquello que hace que Él sea lo que es es la mismidad (Selbstheit) que apunta de este modo a lo más propio, pero que lleva aparejada un movimiento expansivo y constructivo de conformación del Yo. Esta tensión de fuerzas contrarias produce la escisión de ambas fuerzas, la expansiva (repulsión) y la contractiva (atracción), que serán las que, siguiendo las reflexiones de Kant sobre la dinámica en sus Principios metafisicos de la ciencia de la naturaleza (1786), se encuentren luchando entre sí en el despliegue de la naturaleza y por las cuales aparecen los diferentes seres y formas naturales 44 : el vínculo más íntimo de las fuerzas sólo se deshace en un despliegue gradual, y en cada grado de la escisión de fuerzas surge un nuevo ser" 45 . Sólo en el hombre, dirá Schelling, como culminación de la creación se dará una separabilidad total de ambos principios. Ésta será, para Schelling, la posibilidad del mal, basada en la diferencia ontológica entre fundamento y existencia ${ }^{46}$. El hombre, como centro de la creación, puede libremente optar por uno de los dos principios: el expansivo, manteniendo de este modo el "orden natural" o el contractivo, que lo invierte y lo transtorna. La libertad como facultad para el bien y para el mal implicaría que el hombre tiene a su alcance ambas fuerzas y que puede disponer de ellas como guste. La libertad es, pues, poder ${ }^{47}$.

Por lo dicho, sabemos que el propio movimiento por el cual Dios se hace así mismo genera la "realidad" y que en este movimiento el hombre ocupa el lugar central, pero seguimos sin saber qué es exactamente el mal, qué lleva al hombre a hacerlo y, sobre todo, qué sentido y relevancia puede tener la interpretación schellinguiana del mal y la libertad. Para profundizar en esas cuestiones los tres conceptos que aparecían en el texto de Baader de 1807: mismidad, amor propio y elevación constituyen las piezas clave del planteamiento schellinguiano.

\section{Umkehrung (inversión) y Erhebung (elevación)}

La primera palabra clave para tratar de responder a estas tres preguntas es el concepto de "mismidad" (Selbstheit). Schelling afirmará que el mal se hace efecti-

44 Cf. Heuser-Keßler: Die Produktivität der Natur. Scgellings Naturphilosophie und das neue Paradigma der Selbstorganitation in den Naturwissenschaften, Berlin, Dunker und Humboldt, 1986. $45 \mathrm{SW} \mathrm{I} / 7,362 ; 175$.

$46 \mathrm{SW} \mathrm{I} / 7,364 ; 179$.

47 Este será justamente el punto de partida de la crítica de Kierkegaard. Cfr. Kierkegaard, S.: El concepto de la angustia, Alianza, Madrid, 2010, p. 57 y ss. 
vo, y no meramente posible, cuando la "mismidad" se encuentra activada (aktivierte Selbstheit o wirksame Selbstheit ${ }^{48}$. Y dado que la mismidad tiene que ver con lo más propio y, por tanto, con una retracción hacia sí del yo, una "mismidad activada" conllevaría la idea de un movimiento en el que no hay un equilibrio entre contracción y donación, sino donde prima lo contractivo frente a lo expansivo, es decir, un movimiento por el cual queda roto el equilibrio $u$ orden natural y se produce un trastorno o desequilibrio en el mismo. Schelling definirá de este modo el mal "el único concepto correcto del mal, según el cual éste se basa en un trastorno positivo o inversión de los principios, ha sido puesto de nuevo puesto de relieve por Franz von Baader, recurriendo para ello a penetrantes analogías físicas, en concreto, la de enfermedad"49. Y añade una nota al pie en la indica que se está refiriendo a dos textos: "Sobre la afirmación de que no puede haber ningún mal uso de la razón" y "Sobre lo sólido y lo fluido". El primer texto explica, como hemos visto, que, efectivamente puede haber un mal uso de la razón y que la libertad es responsable también del mal y el segundo aborda qué significa este mal uso. En ambos casos el mal queda entendido como inversión del orden (moral, físico) cuyo origen es la voluntad. Sin embargo Baader, aun formulando por primera vez un concepto apropiado del mal y reconociendo la importancia de la razón y del entendimiento, fue incapaz de hacerse cargo de la envergadura de este concepto, al dar mayor revelancia a la función de la sensibilidad.

Tanto perversión (Verkehrtheit) como inversión (Umkehrung) dan cuenta de un movimiento de cambio de posición y/o sentido de algo dado con anterioridad. Construidos sobre la base del verbo "kehren" que significa "cambiar de dirección"50 en el sentido de un volver hacia o un tornar, ambos términos indican un tornarse que es un trastornarse: "verkehren" hace referencia a la acción mediante la cual algo queda alterado, esto es vuelto-otro, o puesto de manera distinta a como estaba inicialmente con un sentido negativo; "umkehren" por su parte tiene el sentido de poner algo boca abajo, de voltearlo o darle la vuelta, de ahí que si el mal es un perversión (Verkehrung) o una inversión (Umkehrung), lo es de un orden que queda trastocado o, literalmente, puesto al revés dando lugar a uno inauténtico y falso. Tal trastocamiento es además para Schelling positivo, lo que conlleva que esta alteración del modo y orden natural no puede ser entendida en términos de deficiencia, falta o privación sino como una modificación de los aspectos formales, pero que mantiene los elementos materiales ${ }^{51}$. Ahora bien, si lo que se altera es el orden dado $\mathrm{y}$, siguiendo las reflexiones sobre los grados de la naturaleza, el hombre ocupa el

\footnotetext{
48 Cf. $S W \mathrm{I} / 7,399-400 ; 265$.

$49 \mathrm{SW} \mathrm{I} / 7,366 ; 185$.

50 Cf. Adelung, J. C.: Grammatisch-Kritisches Wörtebuch der Hochdeutschen Mundart, Digitale Bibliothek (recurso online).

$51 \mathrm{SW}$ I/7, 370; 195.
} 
centro del proceso y como tal tiene en su mano la posibilidad de hacer primar un principio sobre el otro (el contractivo o el expansivo), si se produce un desorden éste debe deberse a que ha roto el equilibrio "natural" y lo rompe precisamente por una "activación" de la mismidad, es decir, cuando su "ser propio", su "ser sí mismo" se impone sobre su relación con los otros seres y con lo que le rodea o, dicho de otra manera, cuando prima lo propio sobre lo ajeno. Esta inversión o catástrofe en el ser se ha dado innegablemente ${ }^{52}$. Schelling empleará un interesante juego de palabras entre la mismidad (Selbstheit), el ansia de ser sí mismo que lleva a la construcción de la identidad y de la personalidad (Sehnsucht) - término este último que, por cierto, Heidegger entenderá vinculado a la palabra "Sucht" que no significa búsqueda, sino, con estrecha relación con respecto a la analogía con la enfermedad realizada por Baader, "enfermedad que tiende a extenderse: enfermo [siech], epidemia [Seuche]"53 - y el egoísmo o egocentrismo (Selbstsucht). Una mismidad "activada" o, siguiendo las palabras de Baader en "Sobre el mal uso de la razón", una "mala mismidad" (schlechten Selbsheit) 54 que provoca una inversión: lo que estaba en el centro, se desplaza a la periferia a causa de la alteración producida por el Yo que, al ocupar el centro, quiere ser el centro mismo. Elige ser el centro, quiere serlo. Y esta acción no es una privación, sino algo positivo, activo, que requiere de una fuerza, también positiva, para hacerlo: "La imperfección, en su sentido metafísico universal, no es el carácter habitual del mal, puesto que éste se encuentra a menudo unido a una excelencia de fuerzad singulares que acompaña mucho más raramente al bien. Por lo tanto, el fundamento del mal no puede reposar sobre algo positivo en general, sino más bien en lo supremamente positivo que contiene la naturaleza, como ocurre de hecho según nuestro punto de vista, según el cual el mal reside en el centro o la voluntad originaria del primer fundamento, ahora manifiestos" 55 .

También para Kant, cuyo texto La Religión dentro de los límites de la mera razón ejerce una notable influencia en la concepción schellinguiana, el mal (Böse) había de ser entendido como inversión o, mejor dicho, como perversión: el filósofo de Königsberg empleará los términos perversitas o Verkehrtheit para referirse a la malignidad (Bösartigkeit) del hombre: "la malignidad [vitiositas, gravitas], o, si se prefiere, el estado de corrupción (corruptio) del corazón humano [...] puede también llamarse la perversidad (perversitas) del corazón humano, pues invierte [umkehrt] el orden moral atendiendo a los motivos impulsores de un libre albedrío, $\mathrm{y}$, aunque con ello puedan aún darse acciones buenas según la ley (legales), sin embargo el modo de pensar está corrompido en su raíz (en lo que toca a la inten-

\footnotetext{
$52 \mathrm{SW} \mathrm{I/7,373;} 201$.

53 Heidegger, M.: Schellings Abhandlung über das Wesen der menschlichen Freiheit, p. 150.

54 KÜGV, 38

$55 \mathrm{SW} \mathrm{I} / 7,369 ; 191$.
} 
ción moral) y por ello el hombre es designado como malo"56. La malignidad consiste así, según Kant, en la perversión llevada a cabo por el hombre que, en lugar de respetar el orden moral, somete todo a su voluntad o, dicho de otro modo, cuando al elegir la máxima de su acción, lo hace atendiendo a sus propios deseos. E1 hombre es así malo solamente cuando "invierte el orden moral de los motivos al acogerlos en su máxima: ciertamente acoge en ella la ley moral junto a la del amor a sí mismo [Selbstliebe]; pero dado que no pueden mantenerse una al lado de la otra como a su condición suprema, hace de los motivos del amor a sí mismo y de las inclinaciones de éste la condición del seguimiento de la ley moral"57. La "mala mismidad" es pues la que impulsa a la voluntad del hombre para hacer efectivo (wirklich) lo que sólo era posible (möglich). Por eso, concederá Schelling al hombre el dudoso privilegio de constituir el único ser que puede hacer irrumpir el mal como mal en la creación.

La inversión del orden produce un desequilibro en el sistema que hace del mal algo parecido a la enfermedad, de ahí la alusión al segundo texto de Baader ${ }^{58}$ cuyas analogías físicas con la enfermedad ayudan a Schelling a comprender qué significa que el mal sea "activo" o "positivo" no porque el mal sea una enfermedad del absoluto, sino porque, como la enfermedad: "ciertamente no es nada en esencia, sino en realidad sólo un simulacro [o "apariencia", Scheinbild] de vida y una manera aparición meteórica [...] y no por ello sin embargo deja de anunciársele al sentimiento en menor medida como algo muy real, así sucede con el mal"59. A causa de la voluntad del Yo se produce un dislocamiento del orden, una ataxia de fuerzas, una falsa unidad. Schelling, tras haber explicado el paso del centro a la periferia que se produce cuando la voluntad propia de la creatura aspira a ser ella misma aquello que dicte leyes e impere en el lugar de la voluntad universal, se referirá de nuevo a Baader, citando un fragmento de Sobre lo sólido y lo fluido: "[...] ahora la yoidad [Ichheit], la individualidad, constituyen de modo general la base, el fundamento o centro natural de toda vida de la creatura; pero en cuanto éste cesa de servir en tanto que centro y aparece como dominador en la periferia, arde en ella como furor tantálico el egocentrismo [Selbstsucht] y el egoísmo [Egoism] (la yoidad inflamada)"60. La enfermedad, como el mal, necesita de un huesped y de una red de fuer-

\footnotetext{
56 Ak VI, 30. Traducción de Felipe Martínez Marzoa en Kant: La Religión dentro de los límites de la mera razón, Madrid, Alianza, 2001, p. 48.

57 Ak VI, 36; 56.

58 Sobre la relación entre el mal, la enfermedad y la relación con la Naturphilosophie remito al lector a Moiso, F.: Vita natura libertà. Schelling (1795-1809), Milán, Mursia 1990, p. 294 y ss; veáse también mi estudio "Ens alienum. El mal visto desde la Naturphilosophie en F.W.J.Schelling" en donde se profundiza la relación entre el mal y la enfermedad y la influencia en y sobre Schelling de las teorías médicas imperantes en su época. En Silvia del Lujan Di Sanza y Diana María López (Eds.): El vuelo del búho. Estudios sobre filosofía del idealismo, Buenos Aires, Editorial Prometeo Libros, 2014. $59 \mathrm{SW} \mathrm{I} / 7,366 ; 185$.

$60 \mathrm{SW}$ I/7, $367 \mathrm{n}$.; trad, modif. $187 \mathrm{n}$.
} 
zas para alcanzar una forma de efectividad: no se trata, pues, de una carencia de salud sino de un desequilibrio de las fuerzas internas que es materialmente el mismo que en el cuerpo sano (son las mismas fuerzas), pero formalmente diferentes (su funcionamiento es diferente). El mal como tal puede entenderse como un no-ente: porque no es, pero tiene, sin embargo una efectividad y, por ello se manifiesta en la naturaleza a través de sus efectos ${ }^{61}$ : "el mal no es en efecto otra cosa que lo relativamente no-ente [Nichseyende], que se presenta como ente [Seyende], y suplanta por tanto a lo verdaderamente ente" 62 .

Según esta vinculación del mal con la enfermedad, el mal ha de ser entendido como una reacción egoísta y egocéntrica del hombre que trata afanosamente de ser el centro del mundo, sin importar los demás. Es el triunfo de la voluntad particular sobre la universal. ¿Pero por qué y cómo pone el hombre su voluntad propia sobre la universal? ¿por qué pudiendo el hombre hacer el bien no lo hace? Porque existe -afirma Schelling - una tendencia natural (natürlicher Hang) del hombre hacia al mal63 o, dicho de otra manera, existe una inclinación del hombre hacia el egoísmo o hacia "mirar por lo propio". Cuando Kant, al comienzo de La Religión dentro de los límites de la mera razón, se refiere con estos mismos términos a la propensión del hombre hacia el mal, entiende propensión (Hang) al fundamento subjetivo de una inclinación, esto es, a una predisposición hacia algo que, tras ser probado produce una inclinación (Neigung) ${ }^{64}$. La propensión al mal asociada al mal tiene que ver según Kant con la tendencia del hombre a invertir el orden moral llevado por el amor a sí mismo (Selbstliebe). Y es éste precisamente el punto principal que vincula los planteamientos de ambos filósofos: para Schelling el movimiento del mal tendrá que ver precisamente con el amor a sí mismo, esto es, con el quererse a sí mismo y a lo otro... pero sólo para sí mismo. Sin embargo, el hombre es más un aprendiz de brujo que un malvado65: no quiere el mal por el mal, sino que si hace prevalecer su voluntad propia sobre la universal es para ser sí mismo y ser sólo para sí, reivindicando de este modo su carácter único e individual frente a lo otro66. Es decir, lo que lleva al hombre al mal es el ansia (Sehnsucht) de ser sí mismo, esto es, una

\footnotetext{
$61 S W \mathrm{I} / 7,377 ; 209$.

$62 \mathrm{SW} \mathrm{I} / 7,459$.

63 Cfr. SW I/7, 381; 219.

64 Ak. VI, 28; 46.

65 También para Kant, la malignidad de la naturaleza humana nada tiene que ver con la maldad, esto es, con una intención de acoger lo malo como malo por motivo impulsor de la máxima, sino en la perversidad del corazón humano. Cf. Ak. VI, 37; 57.

66 Esta será por otro lado, en Hegel la figura lógica del mal: el ser-para-sí (Fürsichseyn). El pecado del origen constituye en Hegel la primera toma de conciencia del hombre como ser distinto, extrañado y alienado de la naturaleza. De este movimiento dirá Hegel: “[...] es el error supremo y más obstinado, el cual se tiene a sí mismo por la verdad suprema, [y] aparece en formas más concretas como libertad abstracta, como puro Yo, y luego -ulteriomente- como el mal". WdL; GW. 21:160.
} 
pasión ciega de sí que le hace pasar de la egoidad (Selbstheit) al egocentrismo (Selbstsucht).

Cuando nos referimos al mal como tal, la voluntad propia de la creatura no permite que se aplique la ley universal alguna, salvo la suya propia, es decir, lo que se pretende es que la voluntad propia se erija en voluntad universal o, dicho de otro modo, la voluntad propia se revela como la voluntad que el individuo tiene de dominio. Desde luego, el mal no se presenta en un primer momento como afán de dominio sino que aparece como búsqueda del interés propio. Cuando, finalmente, se manifiesta como tal, como afán o deseo de dominio sobre el otro, es entonces cuando irrumpe en toda su radicalidad. Es esta comprensión del mal la que distancia a Schelling de la propuesta kantiana.

Invertido el orden, el hombre se considera señor de cuanto hay, y fuera ya del centro, roto el vínculo de fuerzas, eleva e impone su voluntad sobre la creación conformando a partir de las fuerzas desunidas una vida falsa y de mentira "fruto de la intranquilidad y la corrupción"67. El hombre por tanto, impulsado por su egocentrismo, quiere ser Señor de cuanto hay y este "querer ser lo que no es" es lo que le hace caer. De ahí la idea de "caída" o de "pecado original". Esta idea aparecerá en 1810, en las Lecciones privadas de Stuttgart 68 cuando Schelling afirme que, si bien es cierto que el hombre, concebido como la más elevada de las creaturas, estaba llamado a ser Señor del Mundo junto a Dios, trata sin embargo de serlo sin Él y es esta osadía la que le lleva a la caída69: "[...] a fin de convertirse él mismo en fundamento creador y gobernar sobre todas las cosas gracias al poder del centro que tiene dentro de sí "70 el hombre pone la mirada no en el Ser, como debiera, sino en el No-ser, no en el ente (Seyende), sino en el no-ente (Nichtseyende) ${ }^{71}$. Éste es el pecado del hombre: "el instante - dirá Schelling-en que el hombre pasa del auténtico ser al noser, de la verdad a la mentira, de la luz a las tinieblas"72. El mal se relaciona de este modo con una apariencia de vida: el mal introduce la negatividad en el seno del ser, trata de corromperlo desde dentro cuando, desde el interior mismo del hombre, se produce la revuelta de un principio autónomo e independiente que utiliza las mismas fuerzas positivas del bien, es decir que participa de la misma materia que éste pero difiere de él en la forma ${ }^{73}$ al generar un nuevo orden. Lo que se produce a raíz

${ }^{67}$ SW I/7, 365; 183. También para Jacob Böhme el mal producirá una vida falsa y de mentira. Cf. Sex puncta theosophica 3, 6. También en Baader: Sämmtliche Werke, Vol. 13. op.cit. p. 90.

${ }^{68} \mathrm{Y}$ antes en su texto de 1804 Philosophie und Religion, aunque desde una perspectiva de trasfondo platónico.

$69 \mathrm{SW} \mathrm{I} / 7,479$.

$70 S W \mathrm{I} / 7,390 ; 243$.

$71 \mathrm{SW}$ I/7, 390; trad. modif. 241.

$72 S W \mathrm{I} / 7,390 ; 241-243$.

73 "En la totalidad dividida se encuentran los mismos elementos que se hallaban en la totalidad unida; lo material es lo mismo en ambos (desde esta perspectiva, el mal no está más limitado o es peor que 
del mal es la repetición perversa de la armonía universal. No es la presencia "fáctica" de otros principios en el interior del hombre la que produce su descentramiento, sino la inflamación de la propia mismidad (Selbstheit), hinchada con la fuerza que le inyecta el movimiento del principio del Grund como ansia de sí: el hombre se refiere a sí mismo y queda encapsulado. El mal constituye así una "recusación", una negación del orden dado y una transgresión de la norma universal que no da lugar ni a un ser ni a una nada, sino a una generatio aequivoca, esto es, a un no-ser que corroe internamente aquello que la sostiene y que, aunque conforma una imagen ilusoria de la vida, se siente como muy real. Tal era, como veíamos el concepto de la enfermedad: una vacilación entre el ser (Sein) y el no-ser (Nichtsein) que, aunque no real, se da de facto en la efectividad como un no-ente (Nichtseiende) ${ }^{74}$. Ésta es la contradicción del mal: que "en su arrogancia de querer serlo todo, cae en el no-ser"75. Al quedar profanado el vínculo y desplazarse a la periferia, al hacer caer en la mentira y la falsedad, el hombre pierde su libertad76.

El paso que vincula como diferentes fases de un mismo movimiento el ansia (Sehnsucht) de querer ser sí mismo, el egoísmo (Selbstsucht) y el querer serlo todo con el querer todo para sí, conlleva que este intento del hombre - de todos y cada uno de los hombres- de erigirse como centro mismo y hacer que todo gire a su alrededor sea el intento de aquel que trata de dominar lo que le rodea en uso y abuso de su poder, esto es, el movimiento por el cual el hombre trata ilegítimamente de imponer su voluntad. Dos consecuencias tendrá esta elevación de la voluntad y dos elementos importantes confluirán en el concepto de Estado presentado por Schelling. En primer lugar, la pérdida de la unidad natural y armónica hará necesaria la construcción de una unidad artificial (el Estado) y, en segundo lugar, el afán de dominio que caracteriza a cada hombre particular conducirá a la necesaria figura de un "Señor" que legítimamente imponga orden a una sociedad en la que es necesaria la coacción para que sea posible la convivencia 77 .

¿Puede haber por tanto un mal uso de la razón? Leamos a Schelling, influido por Baader, en esta respuesta indirecta a lo afirmado por Jacobi: "la mera reflexión de que el hombre, que es la más perfecta de todas las criaturas visibles, es la única

el bien), pero la parte formal [Formale] es completamente diferente en ambos, aunque esto formal procede precisamente de la propia esencia [Wesen] o de lo positivo mismo [Positiven selber]". SW I/7, $370 ; 195$.

$74 S W \mathrm{I} / 7,366 ; 185 . S W \mathrm{I} / 7,437$.

$75 S W \mathrm{I} / 7,390-391 ; 243$.

$76 \mathrm{SW} \mathrm{I} / 7,391$; trad. modif. 245.

77 Sobre las repercusiones políticas y éticas del problema del mal en el Estado Cf. Carrasco-Conde, A.: "Acertadamente lo expresa el señor schelling [...] ;aqui hay humanidad!". El descubrimiento consciente del otro en la Nueva Deducción del Derecho Natural o el otro elemento de distanciamiento con respecto a Fichte". En Estudios sobre Fichte, número 3, verano 2012. 
capaz del mal, indica que el fundamento de este último no puede encontrarse de ningún modo en la deficiencia o la privación"78. Sabemos que Schelling rechaza que la sensibilidad, "la carne y la sangre" puedan explicar el surgimiento del mal79; sabemos asimismo que la debilidad o inefectividad del entendimiento pueden relacionarse con la falta de virtud o de bondad en las acciones, pero con "no de las acciones posivivamente malas y contrarias a la virtud" 80 . La única alternativa que nos queda reside en la razón y en su relación con la voluntad. Esta relación, que hace que el hombre pueda optar por la elevación de la voluntad, hacen que la razón, "irritada" por el querer, se convierta en instrumento para el mal. Schelling afirmará, sin embargo, que el hombre, aunque movido por su voluntad, activa un principio del mal, no mueve "al propio mal, ni tampoco es una excitación al mal"

La respuesta de los tres autores, Jacobi, Baader y Schelling, no deja de resultar insatisfactoria porque aquellos niños de La cinta blanca con la que comenzábamos estas páginas experimentaban lo que desde Freud se denominará la felicidad del mal. La razón es justamente la que sabe cómo utilizar los medios para lograr su objetivo y la que encuentra, tanto en los preparativos como en la consumación, un placer por el mal en sí mismo. Negar esta realidad del ser humano sólo puede ser llevado a cabo por aquellos que, parafraseando a Schelling, "sólo pueden poner en tela de juicio aquellos que no conocen al hombre en ellos y fuera de ellos más que de modo superficial" 82 . Hay un uso de la razón para hacer el mal por el mal y nuestra es la tarea de interrogarse por lo que sucede en el interior del corazón humano.

Ana Carrasco-Conde

Dpto. Historia de la Filosofía

Facultad de Filosofía

Universidad Complutense de Madrid

anacconde@ucm.es

\footnotetext{
$78 \mathrm{SW} \mathrm{I} / 7,368 ; 191$.

$79 \mathrm{SW} \mathrm{I/7,388;} 237$.

$80 \mathrm{SW} \mathrm{I} / 7,371 ; 197$.

$81 S W \mathrm{I} / 7,401 ; 269$.

$82 \mathrm{SW} \mathrm{I/7,388;237.}$
} 